\title{
Green Synthesis to Develop Iron-Nano Formulations and Its Toxicity Assays
}

\author{
Smital Kulkarni ${ }^{1}$, Nimain Mohanty ${ }^{2}$, Nitin N. Kadam ${ }^{2}$, Niharika Swain ${ }^{3}$, Mansee Thakur ${ }^{4} *$ \\ ${ }^{1}$ Department of Medical Biotechnology, MGMSBS, MGMIHS, Navi Mumbai, India \\ ${ }^{2}$ Department of Pediatrics, MGM Medical College, MGMIHS, Navi Mumbai, India \\ ${ }^{3}$ Department of Oral Pathology, MGM Dental College \& Hospital, Navi Mumbai, India \\ ${ }^{4}$ Department of Medical Biotechnology, MGMSBS \& CRL, MGMIHS, Navi Mumbai, India
}

Received February 13, 2018

Reviewed June 8, 2020

Accepted June 9, 2020

\section{*Correspondence}

Mansee Thakur

Department of Medical Biotechnology, MGMSBS \& CRL MGMIHS, MGM Medical

College \& MGMCET Navi Mumbai, India Tel: +91-022-2743-2890

E-mail: mansibiotech79@gmail.com, mansimgm07@gmail.com
Objectives: In the past few years, herbal medicines have gained popularity over synthetic drugs because of their natural source and minimal side effects which has led to a tremendous growth of phytopharmaceuticals usage. With the development of nanotechnology, it provides alternative approaches to overcome several limitations using nano-formulations. In spite of considerable quantity of antianemic preparations with different iron forms available, currently additives are used and represented in modern pharmaceutical market. Iron deficiency anemia is a major global public health problem which particularly affects pregnant women, children and elderly persons. The situation is complicated because of disadvantages and drug side effects from existing antianemic medicines. There is a great demand for the development of new antianemic preparations. Green synthesis of iron oxide nanoparticles, possess high potential in this field.

Methods: Our study focuses on developing green synthesis of iron oxide nanoparticles (IONPs) of 10-50 nm with spherical shape where different dosages were used $-1 \mathrm{mg} / \mathrm{kg}$, $10 \mathrm{mg} / \mathrm{kg}$ and $100 \mathrm{mg} / \mathrm{kg}$ for exposure in Wistar albino female rats for 28 days. The toxicity was assessed using various parameters such as measurements of the rat body and organ mass, hematology, biochemical evaluation and histopathological examinations.

Results: No significant differences were observed in body and organ weights. Hematological indices also indicated no significant differences whereas biochemical factors showed increase in levels of direct bilirubin and globulin of medium as well as high dose and SGPT levels were increased only in high dose. The major organs (heart, kidney and liver) showed histopathological alterations in 10 and $100 \mathrm{mg} / \mathrm{kg}$ whereas brain showed only in $100 \mathrm{mg} / \mathrm{kg}$. Conclusion: The toxicity of IONPs was found to be more significant when the concentration was increased; however, low doses can be used for further investigation as an antianemic preparation.

Keywords: iron oxide nanoparticles, biosafety, antianemic preparation

\section{INTRODUCTION}

Iron deficiency anemia (IDA) is one of the most common nutritional disorders in the world prevailing in both developed and underdeveloped countries according to the World Health Organization (WHO) data. It is caused by prolonged low levels of iron in the blood may be due to a variety of factors like irondeficient diet, worm infestations, blood loss due to bleeding, intestinal diseases. This condition is mostly significant for the most vulnerable groups of population among which women of reproductive age, pregnant women, children and elderly persons $[1,2]$.

Iron deficiency in developing countries; rely mainly on food crops and plant-based diets. These consist of high level of nonheme iron, which is poorly absorbed in the body as compared to heme iron, found in animal tissues is another reason for iron 
deficiency in the developing countries [3]. The presence of absorption inhibitors like phytic acids, phenolic compounds, and calcium in cereals and pulses also results in the low absorption of iron in the blood. Pharmaceutical market has considerable series of antianemic preparations which relies on use of iron salts like ferrous sulphates, ferrous citrate etc. They are highly reactive and are known to cause severe effects on the gastrointestinal tract and also affect the natural microbiota of the digestive system $[4,5]$.

Hence, there is a requirement for a new kind of a therapy or iron formulation, which can improve the bioavailability of iron in human body by increasing the absorption of iron formulation to treat iron deficiency efficiently. To overcome all the restriction of literature; the researchers, enterprises are passionately investing in nanotechnology. The study of nanotechnology has evolved as a potential to revolutionize idea in the field of science and many more. In addition to this, nanotechnology is one of the leading targeted nutrients, minerals, molecules, or drugs delivery systems, it has a greater credit value in this field. The purpose of our research work, is to focus on the green synthesis of iron oxide nanoparticles which is bio-safe and biocompatible and to study its potential as an antianemic pharmacological substance for new class of drugs. Antianemic preparations development was the benchmark of this work, after studying the toxicity on synthesized iron nanoparticles.

\section{MATERIALS AND METHOD}

\section{Synthesis of iron oxide nanoparticles (IONPS)}

Plant extracts were formulated with ferric chloride solution for the synthesis of nanoparticles. For the synthesis of iron oxide nanoparticles, hydroponically grown Spinaciaoleracea (commonly called as Spinach) leaf extract was used as the reducing agent and mixed in a solution of $\mathrm{FeCl}_{2}, \mathrm{FeCl}_{3}$ and $\mathrm{NaOH}$. There was an immediate color change after the addition of leaf extract to the solution. The solution was centrifuged and the supernatant was discarded and followed by pellet formation. Then pellet was washed with ethanol and centrifuged again to remove any impurities (Fig. 1) [6-8].

\section{Characterization of iron oxide nanoparticles}

The physicochemical properties of nanoparticles are important for their bio-distribution, safety, and efficacy. Character-

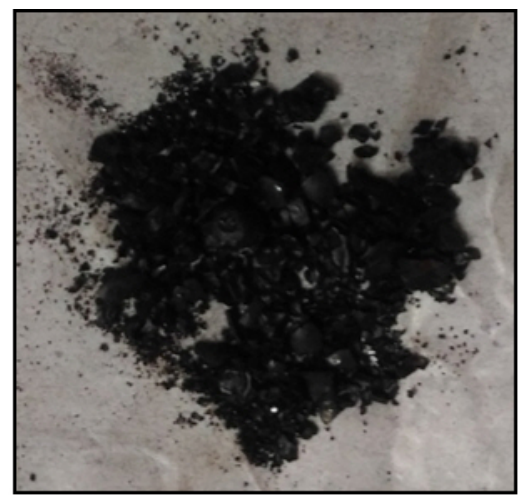

Figure 1. Green synthesized iron oxide nanoparticles.

ization is performed using a variety of analytical techniques, including Scanning Electron Microscopy (SEM - JEOL JSM7600F) for surface morphology and size of the nanoparticles. The X-ray diffraction (XRD - D8 ADVANCE) measurement was performed on X-ray diffractometer (Panalytical Xpert-PRO $3050 / 60$ ) operated at $30 \mathrm{kV}$ and $100 \mathrm{~mA}$ and spectrum was recorded by $\mathrm{CuK} \alpha$ radiation with wavelength of $1.5406 \AA$ in the $2 \theta$ range of $20^{\circ}-80^{\circ}$ andiron content determination was done using Atomic Absorption Spectroscopy (AAS - PEAnalyst800) [6-12].

\section{Treatment of rats}

180-200 gram of Wistar female albino rats were purchased from 'Bombay Veterinary College', Parel, Mumbai and were acclimatized in our institutional animal house for 1 week before the experiment. They were maintained under standard conditions of $12 / 12 \mathrm{~h}$ light/dark cycle at $21^{\circ} \mathrm{C} \pm 3{ }^{\circ} \mathrm{C}$ temperature and $30-70 \%$ relative humidity and fed with standard feed and water. All studies were approved by the Institutional Animal Ethics Committee - Approval No.: 2016/7/12.Sub-acute toxicity study of biosynthesized $\mathrm{Fe}_{2} \mathrm{O}_{3}$ nanoparticles was carried out for 28day with repeated oral dose of $1 \mathrm{mg} / \mathrm{kg}, 10 \mathrm{mg} / \mathrm{kg}$ and $100 \mathrm{mg} /$ $\mathrm{kg}$. The rats were analyzed for various parameters such as body weight, organ weight, hematological indices, biochemical analysis and histopathological studies which were compared with the control group of rats.

\section{Toxicity assessment of IONPs on rat model}

Wistar albino female rats were randomly divided into five groups, including control, vehicle control, low dose (1 mg/kg), 
medium dose $(10 \mathrm{mg} / \mathrm{kg})$ and high dose $(100 \mathrm{mg} / \mathrm{kg})(\mathrm{n}=6$ for each group). Here, control rats were fed with saline and vehicle control group with the solution of $\mathrm{CMC}, \mathrm{FeCl}_{3}, \mathrm{FeCl}_{2}$ and $\mathrm{NaOH}$. IONPs were fed with three different doses low $(1 \mathrm{mg} /$ $\mathrm{kg})$, medium $(10 \mathrm{mg} / \mathrm{kg}) \&$ high $(100 \mathrm{mg} / \mathrm{kg})$ for 28 days.

\section{Statistical analysis}

Data represent mean and standard deviation (SD) of each group of experimental animals. Group mean values of each experiment were compared by the paired $t$-test. $\mathrm{p}<0.05$ was considered to be the level of significance.

\section{RESULTS}

The obtained results using scanning electron microscopy analysis clearly show that IONPs have spherical shape with average diameter of about 10-50 nm (Fig. 2A). The IONPs synthesized from hydroponically grown spinach extract has estimated $40.34 \%$ of Fe content whereas the corresponding plant extract has estimated Fe content in $0.0007 \%$ ppm level using Atomic absorption spectroscopy. XRD analysis was carried out for structural characterization of biosynthesized nanoparticles. XRD of IONPs has showed two peaks $-33.09^{\circ} 2 \theta$ and $35.56^{\circ} 2 \theta$. Both of these peaks denote presence of hematite $\left(\mathrm{Fe}_{2} \mathrm{O}_{3}\right)$ structure (Fig. 2B).

One of the main purposes of the current study was to evaluate the potential toxicity of IONPs. In order to obtain detailed information of toxicity, we performed in vivo serum biochemical analysis, blood chemistry and histopathological examination.

\section{Body \& organ weight}

The weight of rats from each group were recorded before starting the treatment i.e. on day 0 and after treatment i.e. on day 28. On sacrifice, no significant differences in body weights and organ weights were recorded compared to control ones ( $\mathrm{n}$ =6) (Fig. 3).

\section{Hematological analysis}

Several important hematology markers including the white blood cell count (WBC), red blood cell count (RBC), hemoglobin $(\mathrm{HB})$, mean corpuscular hemoglobin $(\mathrm{MCH})$ and mean corpuscular hemoglobin concentration (MCHC) etc were recorded at day 0 and 28 , which were selected for further toxicity and compared with the control rat observations presented in Table 1.

\section{Biochemical examination}

Oral administration of IONPs induced marked increase of direct bilirubin and globulin levels of samples administered with medium as well as high dose whereas SGPT levels show significant differences only in high dose. No significant differences were observed in renal function test (Table 2) [14].

\section{Histopathological studies}

Rat tissue sections were prepared and observed under a light microscope for morphological changes following exposure to $1 \mathrm{mg} / \mathrm{kg}, 10 \mathrm{mg} / \mathrm{kg}$ and $100 \mathrm{mg} / \mathrm{kg}$ of IONPs. The histological examinations of rat when exposed with $10 \mathrm{mg} / \mathrm{kg}$ revealed
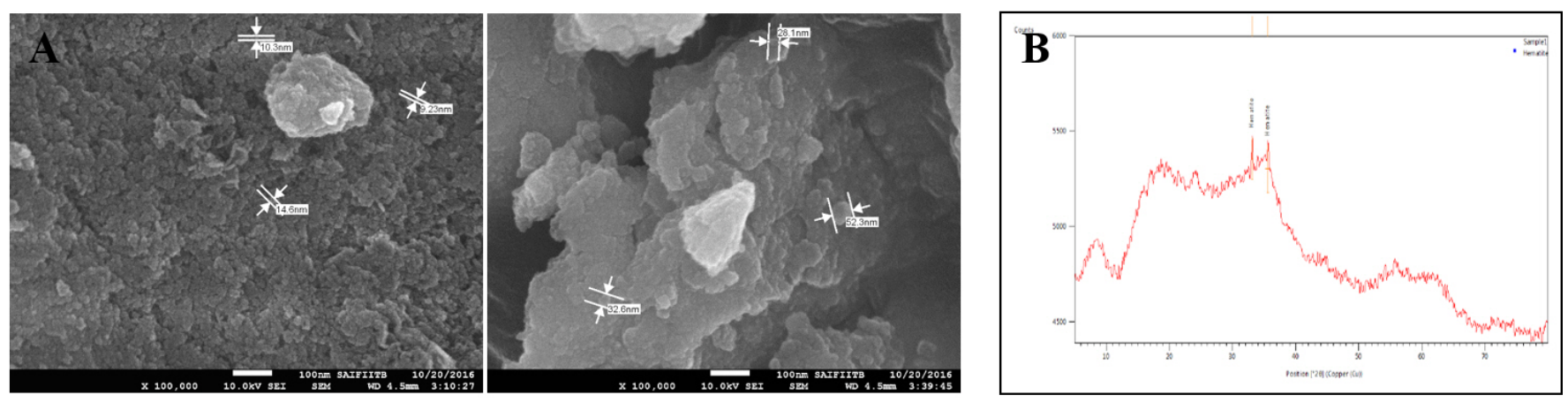

Figure 2. (A) Representing SEM images of green synthesized nanoparticles showing 10-50 nm in size and spherical in shape and (B) showing the state of nanoparticles as hematite (IONPS) [8, 13]. 

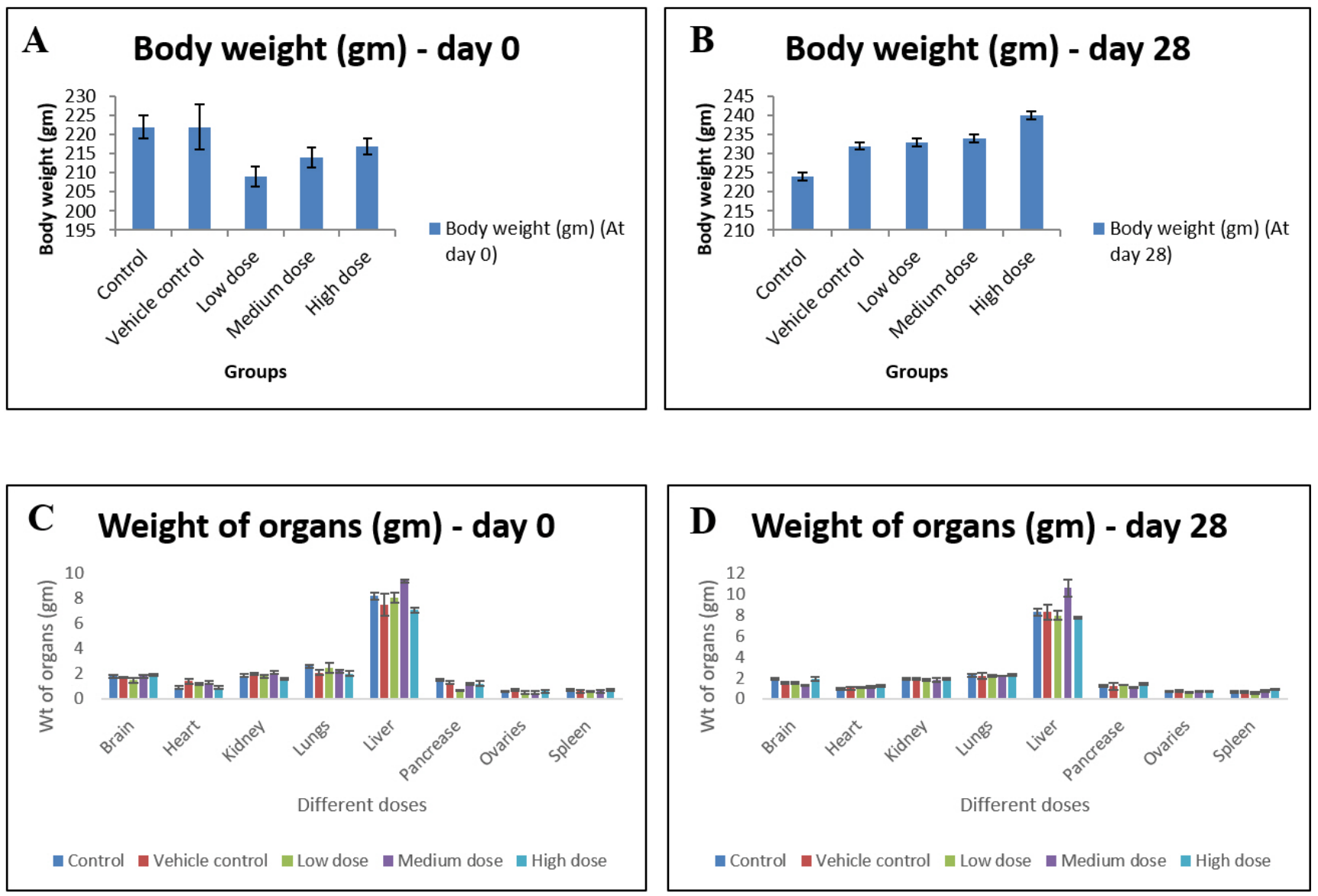

Figure 3. (A-D) Body weight and relative organ weight before and after oral administration of IONP at 0 and 28 days. Data are expressed as means $\pm S D$ of the mean $(n=6)$. $\alpha$ is significant at $p<0.05$ relative to the control.

Table 1. Effect of different dosage of IONPs on hematological indices (WBC, RBC, HGB, HCT, MCV, MCH, MCHC and PLT) in Wistar rat at day 28

\begin{tabular}{lrrrrr}
\multicolumn{1}{c}{ Tests } & Control & Vehicle control & Low dose & Medium dose & High dose \\
\hline $\mathrm{WBC}\left(* 10^{3} / \mu \mathrm{L}\right)$ & $8.4 \pm 1.1$ & $9.2 \pm 4.3$ & $6.7 \pm 1.9$ & $8.2 \pm 1.5$ & $12 \pm 6.7$ \\
$\mathrm{RBC}\left(* 10^{6} / \mu \mathrm{L}\right)$ & $7.7 \pm 0.3$ & $7.6 \pm 0.3$ & $7.2 \pm 0.8$ & $8.2 \pm 1.2$ & $14.5 \pm 2.3$ \\
$\mathrm{HGB}(\mathrm{g} / \mathrm{dL})$ & $16.2 \pm 1.5$ & $13.5 \pm 0.7$ & $13.3 \pm 1.8$ & 4.9 & $13.8 \pm 1.5$ \\
$\mathrm{HCT}(\%)$ & $46.7 \pm 1.8$ & $50.5 \pm 2.6$ & $49.9 \pm 6.1$ & $56.2 \pm 8.0$ & $47.2 \pm 5.4$ \\
$\mathrm{MCV}(\mathrm{fL})$ & $60.3 \pm 2.7$ & $66.8 \pm 0.8$ & $69.2 \pm 1.8$ & $68.2 \pm 0.2$ & $62.7 \pm 0.6$ \\
$\mathrm{MCH}(\mathrm{pg})$ & $18.4 \pm 0.3$ & $17.8 \pm 0.2$ & $18.4 \pm 0.8$ & $17.6 \pm 0.4$ & $18.6 \pm 0.5$ \\
$\mathrm{MCHC}(\mathrm{g} / \mathrm{dL})$ & $31.8 \pm 1.6$ & $26.7 \pm 0.1$ & $26.7 \pm 0.6$ & $28.1 \pm 0.6$ & $29.2 \pm 0.4$ \\
$\mathrm{PLT}\left(* 10^{3} / \mu \mathrm{L}\right)$ & $871 \pm 5.4$ & $789 \pm 4.6$ & $939 \pm 2.3$ & $777 \pm 5.2$ & $638 \pm 3.1$ \\
\hline
\end{tabular}

vacuolar degeneration of cardiomyocytes in the heart (Fig. 4N), Kidney shows dilated and congested blood vessels (Fig. 4O) and liver shows nuclear degeneration of hepatocytes (Fig. 4P). These inimical cellular alterations were non-incident in the control group as well as in the vehicle group (Fig. 4A-H). Whereas exposure of $100 \mathrm{mg} / \mathrm{kg}$ shows abnormal histopathological gross lesions in all major organs like brain shows congested blood vessels and increased nuclear condensation, heart and kidney shows congested blood vessels and renal tissues. Liver shows congested blood vessels and mononuclear cell infiltration (Fig. 4Q-T). The results of this experimental study indicated that IONPs in mentioned concentration $(10 \mathrm{mg} / \mathrm{kg}, 100 \mathrm{mg} / \mathrm{kg}$ ) 
Table 2. Effect of different dosage of IONPs on the activity of LFT \& RFT in Wistar rat at day 28

\begin{tabular}{|c|c|c|c|c|c|}
\hline Tests & Control & Vehicle control & Low dose & Medium dose & High dose \\
\hline \multicolumn{6}{|l|}{ LFT } \\
\hline Total bilirubin (mg/dL) & $0.4 \pm 0.05$ & $0.4 \pm 0.1$ & $3.2 \pm 0.1$ & $0.9 \pm 0.3$ & $0.9 \pm 0.5$ \\
\hline Direct bilirubin (mg/dL) & $0.4 \pm 0.09$ & $0.5 \pm 0.05$ & $2.1 \pm 3.0$ & $0.6 \pm 0.2$ & $0.5 \pm 0.1$ \\
\hline SGOT (mg/dL) & $237.2 \pm 85.1$ & $248 \pm 18.4$ & $272.6 \pm 2.1$ & $336 \pm 33.0$ & $262.5 \pm 34.8$ \\
\hline Total protein $(\mathrm{g} / \mathrm{dL})$ & $7.9 \pm 0.4$ & $8.5 \pm 0.6$ & $9.4 \pm 2.1$ & $7.5 \pm 0.7$ & $8.2 \pm 0.3$ \\
\hline Albumin (g/dL) & $4 \pm 0.5$ & $4.3 \pm 0.2$ & $6.9 \pm 0.5$ & $6.6 \pm 0.2$ & $5.5 \pm 0.2$ \\
\hline Globulin (g/dL) & $3.7 \pm 0.2$ & $4.2 \pm 0.5$ & $2.5 \pm 0.4$ & $2.64 \pm 0.5$ & $2.6 \pm 0.1$ \\
\hline Alkaline phosphate (mg/dL) & $168.1 \pm 33.8$ & $93.9 \pm 21.5$ & $50.9 \pm 51.8$ & $129.5 \pm 31.4$ & $99.5 \pm 26.6$ \\
\hline SGPT (mg/dL) & $55.8 \pm 2.9$ & $52 \pm 3.6$ & $64.5 \pm 4.4$ & $72.3 \pm 6.5$ & $42.3 \pm 2.5$ \\
\hline \multicolumn{6}{|l|}{ RFT } \\
\hline BUN (mg/dL) & $16.3 \pm 2.9$ & $15.3 \pm 1.5$ & $20.7 \pm 0.6$ & $17.3 \pm 1.0$ & $21.7 \pm 1.6$ \\
\hline Urea (mg/dL) & $2.6 \pm 6.4$ & $31.4 \pm 1.2$ & $44.3 \pm 1.2$ & $37 \pm 2.0$ & $46.5 \pm 3.4$ \\
\hline Creatinine (mg/dL) & $1.1 \pm 0.2$ & $1.1 \pm 0.2$ & $0.9 \pm 0.1$ & $0.9 \pm 0.1$ & $1.2 \pm 0.1$ \\
\hline Uric acid (mg/dL) & $3.6 \pm 1.1$ & $3.8 \pm 0.3$ & $8.7 \pm 2.0$ & $6.4 \pm 1.5$ & $3 \pm 1.1$ \\
\hline
\end{tabular}

shows significant effect on the histological analysis.

\section{DISCUSSION}

The aim of the present study was to assess and investigate the toxic impacts of different doses of our biosynthesized IONPs on Wistar albino female rats. The IONPs were successfully synthesized by biological method using Spinacia oleracea leaves extract and characterized using sophisticated instruments which revealed 10-50 $\mathrm{nm}$ sized particles with spherical shape by SEM. XRD revealed hematite $\left(\mathrm{Fe}_{2} \mathrm{O}_{3}\right)$ state of nanoparticles and AAS estimated $40.34 \%$ Fe content in the sample. Whenever, there is usage of nanoparticles, the main concern is its toxicity influence. Hence, in this study, the synthesized IONPs were fed in three different doses - 1, 10 and $100 \mathrm{mg} / \mathrm{kg}$ for 28 days. To evaluate the impact of toxicity in rats various parameters were studied such as body and organ weight, hematological indices, biochemical studies and histopathological studies.

The effects of IONPs on body and organ weight of rats does not show any loss or gain in weight. Kumari et al, revealed neither loss in body weight nor any abnormal signs or symptoms on repeated administration of $\alpha-\mathrm{Fe}_{2} \mathrm{O}_{3} \mathrm{NP}$ for 28 days similar to that of our results [15]. However, another study showed contrast findings to ours as Wang et al observed significant weight loss and gastro-intestinal damage with severe symptoms [16]. With respect to hematological indices, the evaluation did not show any significant differences in either of the doses. These findings are in accordance with observations of our previous study [13]. No obvious signs of inflammatory responses or toxic reactions that could be attributed to these doses were found [17-19]. Whereas for biochemical factors, present findings are in contrast with observations of our previous work [13]. In accordance to our findings, Gillian Federici et al revealed no significant alterations were found in hematological profile but contrast with our findings with respect to biochemical parameters such as blood cells count and enzymes activity [20].

Studies of nanotoxicology performed in vivo using correct doses and exposure routes are of greater significance due to the complexity of systemic phenotypic reaction and the physiological/anatomic effect than can be translated from animal model to human exposure. Hence, it was also point of concern to investigate the effects of toxicity at the tissue level. The histopathological studies of major organs - heart, kidney and liver showed abnormal alterations when compared to the control rats in 10 and $100 \mathrm{mg} / \mathrm{kg}$ doses and brain in $10 \mathrm{mg} / \mathrm{kg}$ dose. In contrast to our findings, higher accumulation of IONPs (dose of $1000 \mathrm{mg} / \mathrm{kg}$ for 28 days) was found in liver of rats causing congestion of portal tract whereas kidneys and brain were not affected [21]. Other literature demonstrated the assessment of superparamagnetic iron oxide nanoparticles on SD rats that revealed no alterations in histopathological and biochemical parameters [22].

Hematological profile and biochemical parameters such as blood cells count and enzymes activity are used to provide use- 
Brain
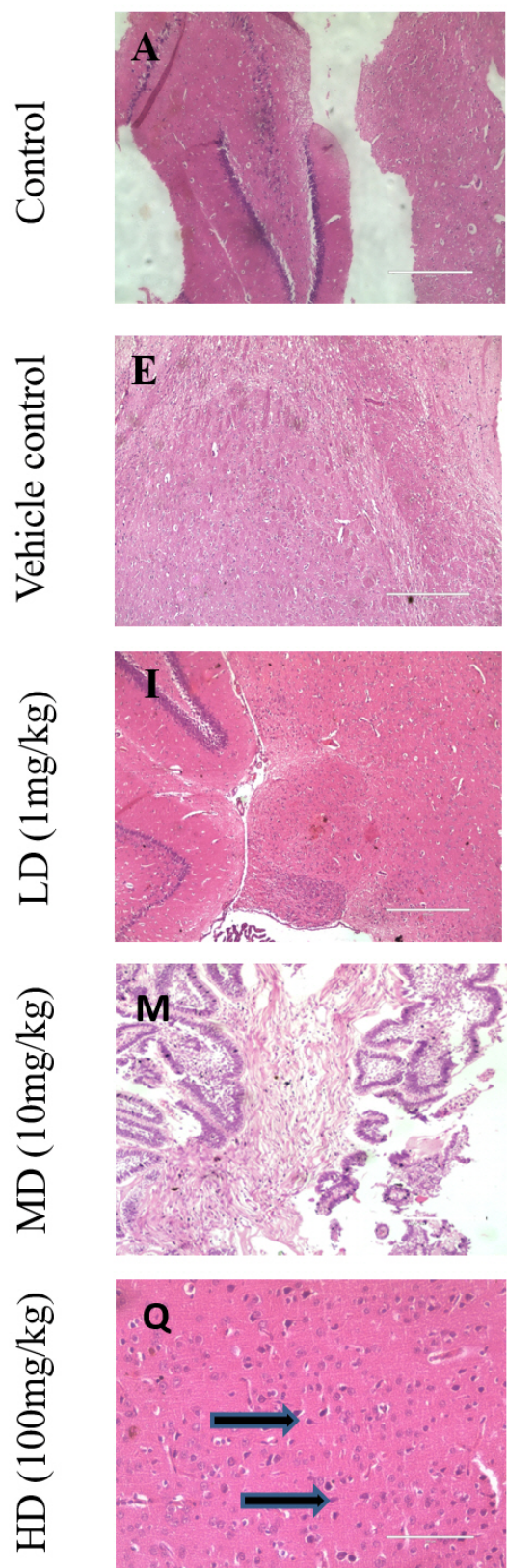

Heart
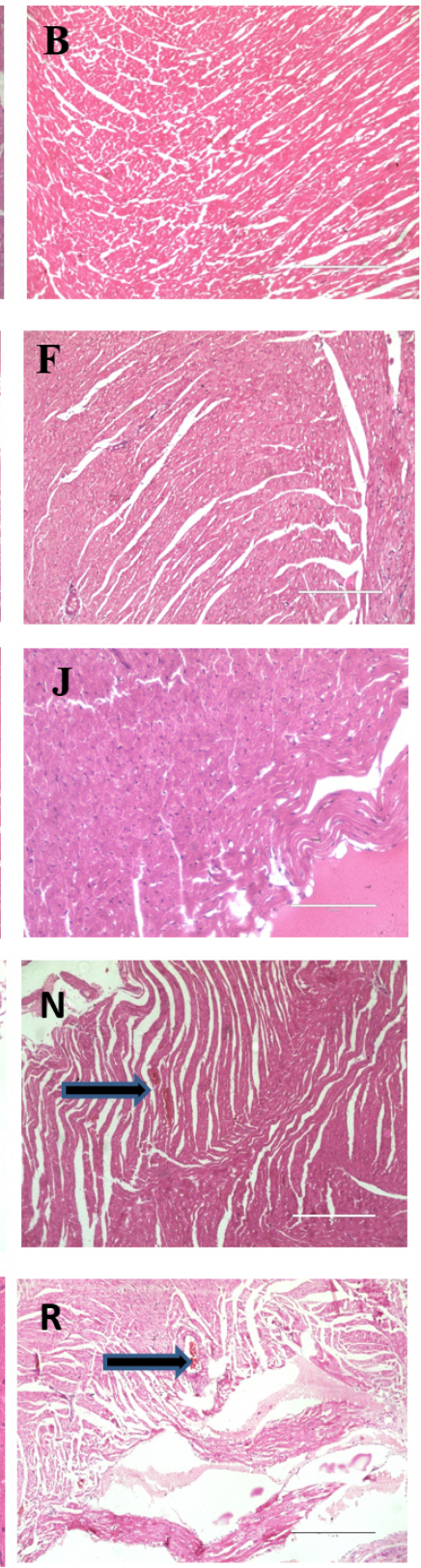

Kidney
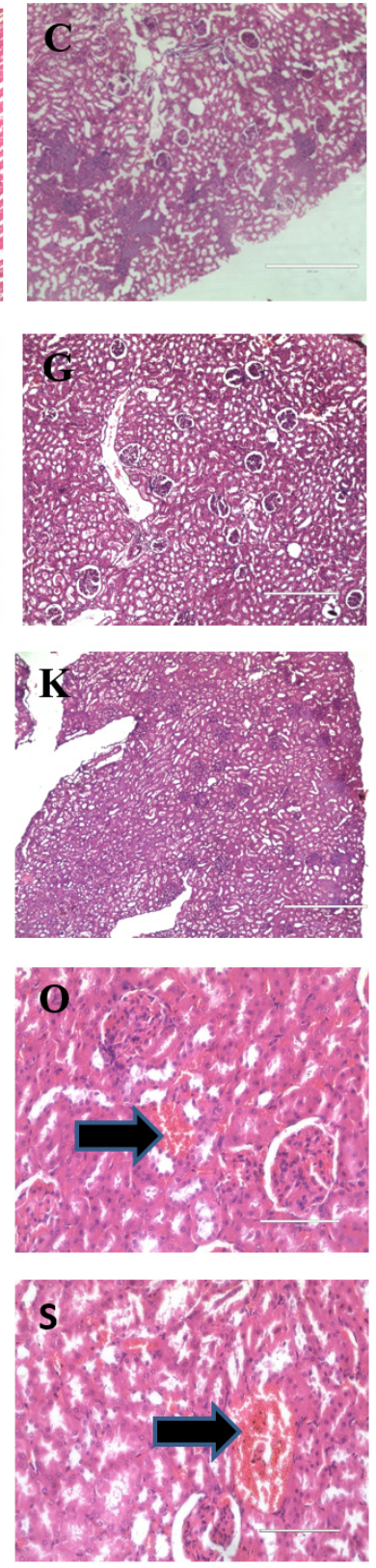

Liver
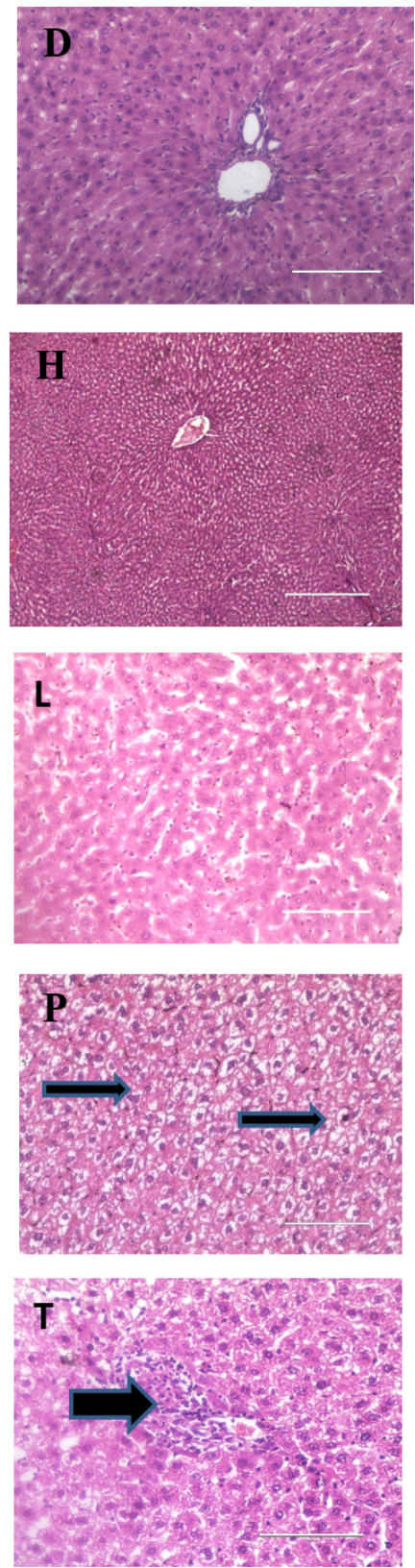

Figure 4. Histological evaluation of IONPs on various tissues. Representative images of brain, heart, kidney and liver of control, vehicle control and IONPs ( $1 \mathrm{mg} / \mathrm{kg}, 10 \mathrm{mg} / \mathrm{kg}, 100 \mathrm{mg} / \mathrm{kg}$ ) treated groups where organs collected after 28 days of oral administration. Sections were stained with $\mathrm{H} \& \mathrm{E}$ and observed under a light microscope at 10X \& 40X magnification.

ful information for diagnosis in routine clinical evaluation of the state of health of a patient and animals. There were no abnormal findings at hematological parameters and biochemical parameters except direct bilirubin, globulin and SGPT levels in treated-rats. The unchanged levels of BUN, urea, creatinine and uric acid in the present study indicated normal renal functions in the IONPs exposed group. However, the oral administration of a moderate and high dose of IONPs (10 mg/kg, $100 \mathrm{mg} / \mathrm{kg}$ ) induced a marked increase of toxicity at tissue level $[23,24]$.

\section{CONCLUSION}

The present study focused on the green synthesis and characterization of IONPs from spinach and its toxicity assessment 
with the exposure of different dosages to experimental rats. An effective method for green synthesis of metallic IONPs using leaf extracts of spinach was established and was characterized by SEM, XRD and AAS. SEM results revealed that the obtained particles were spherical in shape with an average diameter of 10-50 $\mathrm{nm}$. XRD peaks indicated that the synthesized nanoparticles were found to be in $\alpha-\mathrm{Fe}_{2} \mathrm{O}_{3}$ state and crystalline in nature. AAS analysis confirms content of iron. In the present study, different dosages were used $1 \mathrm{mg} / \mathrm{kg}, 10 \mathrm{mg} / \mathrm{kg}$ and $100 \mathrm{mg} / \mathrm{kg}$ for exposure in Wistar albino female rats for 28 days. Based on the measurements of the rat body and organ mass, haematology, biochemical evaluation and histopathological examinations indicated toxicity for $10 \mathrm{mg} / \mathrm{kg}$ and $100 \mathrm{mg} / \mathrm{kg}$. Therefore, we can conclude that though, the toxicity of IONPs is more significant when the concentration is increased; less than $10 \mathrm{mg} / \mathrm{kg}$ dose can be used for further investigation as an antianemic preparation at the pharmaceutical industry in the near future. The derived green biosynthesis of IONPs protocol by utilizing plant extracts has several advantages over chemical synthesis: (1) sustainable availability of materials for large scale synthesis of NPs; (2) plant extract does not contain toxic substances, and (3) various bioactive molecules availability in different plant species.

\section{CONFLICT OF INTEREST}

The author declares no conflict of interest.

\section{ORCID}

Smital Kulkarni, https://orcid.org/0000-0002-2952-5850

Nimain Mohanty, https://orcid.org/0000-0001-5013-4793

Nitin Kadam, https://orcid.org/0000-0002-4257-6601

Niharika Swain, https://orcid.org/0000-0002-8500-7724

Mansee Thakur, https://orcid.org/0000-0003-4743-1476

\section{REFERENCES}

1. World Health Organization. Iron deficiency anaemia: assessment, prevention, and control: a guide for programme managers. Geneva: WHO; 2001. 114 p.

2. Lewis SM, Emmanuel JC. Global concept of iron deficiency. In: Yehuda S, Mostofsky D, editors. Iron deficiency and overload. Totowa: Humana Press; 2009. p. 299-312.

3. Hurrell R, Egli I. Iron bioavailability and dietary reference values. Am J Clin Nutr. 2010;91(5):1461S-7S.
4. Stoltzfus RJ, Dreyfuss ML. Guidelines for the use of iron supplements to prevent and treat iron deficiency anemia. Washington: ILSI Press; 1998. 4 p.

5. Saha L, Pandhi P, Gopalan S, Malhotra S, Saha PK. Comparison of efficacy, tolerability, and cost of iron polymaltose complex with ferrous sulphate in the treatment of iron deficiency anemia in pregnant women. MedGenMed. 2007;9(1):1.

6. Balamurugan M, Saravanan S, Soga T. Synthesis of iron oxide nanoparticles by using Eucalyptus globulus plant extract. E-J Surf Sci Nanotechnol. 2014;12:363-7.

7. Omidvari A, Manteghi F, Sohrabi B, Afra Y. A herbal extract for the synthesis of magnetite nanoparticles. In: Seijas JA, Pilar Vázquez Tato M, Lin SK, editors. The 18th international electronic conference on synthetic organic chemistry. Basel: MDPI; 2014. p. 1-4.

8. Kulkarni S, Abraham PS, Mohanty N, Kadam NN, Thakur M. Sustainable raft based hydroponic system for growing spinach and coriander. In: Pawar PM, Ronge BP, Balasubramaniam R, Seshabhattar S, editors. Techno-societal 2016. Cham: Springer International Publishing; 2018. p. 117-25.

9. Mahdavi M, Namvar F, Ahmad MB, Mohamad R. Green biosynthesis and characterization of magnetic iron oxide $\left(\mathrm{Fe}_{3} \mathrm{O}_{4}\right)$ nanoparticles using seaweed (Sargassum muticum) aqueous extract. Molecules. 2013;18(5):5954-64.

10. Pattanayak M, Nayak PL. Green synthesis and characterization of zero valent iron nanoparticles from the leaf extract of Azadirachta indica (Neem). World J Nano Sci Technol. 2013;2(1):6-9.

11. Pattanayak M, Nayak PL. Ecofriendly green synthesis of iron nanoparticles from various plants and spices extract. Int J Plant Anim Environ Sci. 2013;3(1):68-78.

12. Latha N, Gowri M. Bio synthesis and characterisation of Fe3o4 nanoparticles using caricaya papaya leaves extract. Int J Sci Res. 2014;3(11):1551-6.

13. Smital K, Niharika S, Mansee T. Sub-acute toxicity assessment of green synthesized hematite nanoparticles ( $\alpha$-Fe2O3NPs) using Wistar rat. Res J Biotechnol. 2020;15(4):121-35.

14. Akbary P. Consideration of blood serum biochemical parameters of yellow fin sea bream (Acantopagrus latus Houttuyn, 1782) and orange-spotted grouper (Epinephelus coioides Hamilton, 1822). Adv Biol Chem. 2014;4(6):407-13.

15. Kumari M, Rajak S, Singh SP, Kumari SI, Kumar PU, Murty US, et al. Repeated oral dose toxicity of iron oxide nanoparticles: biochemical and histopathological alterations in different tissues of rats. J Nanosci Nanotechnol. 2012;12(3):2149-59.

16. Wang B, Feng W, Wang M, Wang T, Gu Y, Zhu M, et al. Acute toxicological impact of nano- and submicro-scaled zinc oxide powder on healthy adult mice. J Nanopart Res. 2008;10(2):26376. 
17. Gaharwar US. Paulraj R. Iron oxide nanoparticles induced oxidative damage in peripheral blood cells of rat. J Biomed Sci Eng. 2015;8(4):274-86.

18. Naeshiro I, Ishimura Y, Chatani F, Sato S. Possible mechanism for the anaemia induced by gentamicin in rats. Comp Haematol Int. 1997;7(4):220-5.

19. Szalay B. Iron oxide nanoparticles and their toxicological effects: in vivo and in vitro studies [dissertation]. [Szeged]: University of Szeged; 2012. 44 p.

20. Federici G, Shaw BJ, Handy RD. Toxicity of titanium dioxide nanoparticles to rainbow trout (Oncorhynchus mykiss): gill injury, oxidative stress, and other physiological effects. Aquat Toxicol. 2007;84(4):415-30.

21. Reddy UA, Prabhakar PV, Mahboob M. Biomarkers of oxidative stress for in vivo assessment of toxicological effects of iron oxide nanoparticles. Saudi J Biol Sci. 2017;24(6):1172-80.

22. Yu Q, Xiong XQ, Zhao L, Xu TT, Bi H, Fu R, et al. Biodistribution and toxicity assessment of superparamagnetic iron oxide nanoparticles in vitro and in vivo. Curr Med Sci. 2018;38(6): 1096-102.

23. Kim WY, Kim J, Park JD, Ryu HY, Yu IJ. Histological study of gender differences in accumulation of silver nanoparticles in kidneys of Fischer 344 rats. J Toxicol Environ Health A. 2009;72(21-22):1279-84.

24. Thakur M, Gupta H, Singh D, Mohanty IR, Maheswari U, Vanage G, et al. Histopathological and ultra structural effects of nanoparticles on rat testis following 90 days (Chronic study) of repeated oral administration. J Nanobiotechnology. 2014;12:42. 